\title{
A review of the effect of hydrogen addition on the performance and emissions of the compression - ignition engine
}

\begin{abstract}
Diesel engines produce high emissions of smoke, particulate matter and nitrogen oxide. The challenge now is to decrease exhaust emissions without making any major changes on their mechanical configuration. Therefore, adding hydrogen becomes a natural choice to enhance the performance and emissions of diesel engines. This paper offers an overview of the effect of hydrogen additional to the diesel engine. The overall finding from the review suggests that the airi fuel ratio, engine speed, and engine load play a key role in the performance and emission of diesel engines with hydrogen enrichment. The brake thermal efficiency (BTE), brake power output, brake means effective pressure (BMEP), and specific energy consumption (SEC) are dependent on the operating conditions of the engine when adding the hydrogen. It is also found that increasing the percentage of hydrogen will affect emissions, so that the reduction in unburned hydrocarbon $(\mathrm{HC})$, carbon monoxide $(\mathrm{CO})$, carbon dioxide (CO2), particulate matter (PM), and smoke are observed when adding the hydrogen. However, nitrogen oxide (NOx) is increased when enriching $\mathrm{H} 2$, but this increase in NOx can be controlled by numerous injections, exhaust gas recirculation (EGR) or water injection as well as exhaust after-treatment as has been discussed in this paper.
\end{abstract}

Keyword: Engine; Hydrogen; Diesel 